\title{
A MULHER COMO UM SUJEITO VIOLÁVEL NO CÁRCERE: UMA ANÁLISE SÓCIO-JURÍDICA DA MULHER NO CÁRCERE, À LUZ DA TEORIA DE PIERRE BOURDIEU
}

\author{
Lorena Araújo Matos ${ }^{1}$ \\ Thiago Augusto Galeão de Azevedo ${ }^{2}$
}

\section{RESUMO}

O estudo proposto tem como objeto a análise do encarceramento feminino e a sua relação com uma dominação do masculino por meio de uma violência simbólica. Objetiva-se, em níveis gerais, analisar a mulher no cárcere, correlacionando-o com uma perspectiva teórica de Pierre Bourdieu. Busca-se responder em que medida o cárcere é uma instituição permeada por preceitos masculinos construídos e solidificados em detrimento da mulher, expondo-a ao nível de ser matável? Para tanto, realizou-se uma análise teórica sobre a teoria de Pierre Bourdieu, seguida de uma análise sócio-jurídica da mulher no cárcere. Utiliza-se, metodologicamente, da pesquisa bibliográfica.

PALAVRAS-CHAVE: dominação masculina; violência simbólica; mulher; encarceramento feminino; violável.

\section{WOMAN AS A VIOLABLE SUBJECT IN Jail: A SOCIO-LEGAL ANALYSIS OF WOMAN IN JAIL, IN THE LIGHT OF PIERRE BOURDIEU THEORY}

\begin{abstract}
The proposed study has as its object the analysis of female incarceration and its relationship with a male domination through symbolic violence. The objective is, in general levels, to analyze the woman in the prison, correlating it with a theoretical perspective of Pierre Bourdieu. To what extent is jail an institution permeated by male precepts built and solidified to the detriment of women, exposing her to the level of being killable? Therefore, a theoretical analysis of Pierre Bourdieu's theory was carried out, followed by a socio-legal analysis of women in prison. Methodologically, it is used the bibliographical research.
\end{abstract}

KEYWORDS: male domination; symbolic violence; woman; female imprisonment; violable.

\section{INTRODUÇÃO}

\footnotetext{
${ }^{1}$ Mestra em Direito Constitucional (IDP). Especialista em Direito Penal e Processo Penal (Damásio). Professora Universitária. Advogada (OAB/DF). CA 09, Ed. San Diego, ap 109, 71503-509, Brasília/DF. 1.maatos@gmail.com.

${ }^{2}$ Doutorando em Direito - UNB, mestre em Direito - CESUPA. Especialista em Direito Civil - PUC MG, Professor da Universidade Federal de Mato Grosso. Advogado (OAB/MT). Rua Waldir Rabelo, 485, ap. 201, CEP 7860000, Barra do Garças/MT, thiagogaleao@ hotmail.com.
} 
O presente artigo tem como objetivo analisar os principais elementos da chamada Dominação Simbólica, fenômeno próprio ao filósofo Pierre Bourdieu, à luz de sua teoria da Dominação Masculina, correlacionando com o encarceramento feminino no Brasil.

Expor-se-á, para tanto, em uma primeira seção, os elementos centrais da teoria da Dominação Masculina, perpassando-se, principalmente, pelo fenômeno da Dominação Simbólica, Poder Simbólico, Violência Simbólica e Habitus.

Em um segundo momento, após o fornecimento do citado substrato teórico, analisarse-á a incorporação da referida violência simbólica e a sob a perspectiva de gênero e raça como o sistema prisional feminino é pautado por questões estruturantes de invisibilidade e exclusão por parte do Poder Público.

\section{A DOMINAÇÃo MASCULINA: DOMINAÇÃO SIMBÓliCA, PODER SIMBÓLICO, VIOLÊNCIA SIMBÓLICA E HABITUS}

Inicialmente, deve-se apresentar o contexto geral da obra a ser explorada, $A$ Dominação Masculina: A condição feminina e a violência simbólica. Escrita pelo citado autor, Pierre Bourdieu, tal obra é comparada a uma análise de laboratório, por analisar, especificamente, uma sociedade de tradição mediterrânea, a Cabília, através de suas estruturas objetivas e formas cognitivas.

A referida sociedade é marcada por uma naturalidade em relação à divisão sexual. Bourdieu comenta que esta divisão aparece como pertencente à "ordem das coisas", trata-se de algo inevitável, normal, enraizado ao ponto de ser considerado natural. Divisão esta objetivada nas coisas e incorporada nos corpos e nos habitus ${ }^{3}$ dos agentes.

A citada tradição da Cabília é originada de um "mito fundador", que embasa a citada divisão sexual. $\mathrm{O}$ referido mito exerce influência não somente nas relações de trabalho, mas também na ordem social, ultrapassando-a, no sentido de alcançar, nas palavras do autor, uma “ordem cósmica”, uma vez que se torna intrínseco à figura do homem e da mulher.

O referido mito conta a história de um encontro de um homem e uma mulher em uma fonte. A mulher aguardava para apanhar um pouco de água, quando um homem chegou e a empurrou. Este seria o primeiro contato entre um homem e uma mulher. Ao ser empurrada, a

\footnotetext{
3 “A constância dos habitus que daí resulta é, assim, um dos fatores mais importantes da relativa constância da estrutura da divisão sexual de trabalho: pelo fato de serem estes princípios transmitidos, essencialmente, corpo a corpo, aquém da consciência e do discurso, eles escapam, em grande parte, às tomadas de controle consciente e, simultaneamente, às transformações ou às correções [...]”' (Bourdieu, 2014, p. 133).
} 
mulher caiu e com a queda suas coxas ficaram à mostra, sendo observadas pelo homem, que de pronto percebeu que eram diferentes das suas. Trata-se do momento em que a mulher decidiu ensinar ao homem o que era prazer sexual, acariciando seu pênis, até este ficar ereto e atingir o prazer maior.

A partir do referido fato, o homem começou a seguir a mulher, pois esta era mais sábia que ele. Entretanto, um dia o homem resolveu mostrar à mulher que sabia fazer as "coisas" também, foi quando se deitou sobre ela e sentiu o mesmo prazer, mostrando-a que na fonte é ela quem manda, mas na casa ele quem dava as ordens.

Bourdieu destaca que o referido "mito fundador" institui a chamada "oposição constituinte", que se trata da oposição entre natureza e cultura. A sexualidade da natureza é exercida na fonte, lugar próprio do feminino, enquanto que a sexualidade da cultura se exerce na casa, lugar eminentemente masculino. À sexualidade da natureza é oposta a sexualidade da cultura, no sentido de domesticação da mulher pelo homem, uma vez que a casa representava o lugar da "natureza cultivada".

O feminino era relacionado à natureza, à selvageria, que deveria ser controlada, podada pela cultura, pelo masculino. Como se a selvageria da mulher precisasse ser domesticada. O lugar do referido controle era exercido em casa, uma vez que este era o espaço próprio do masculino, da subordinação da mulher ao homem.

Pode-se perceber que o referido mito influencia na origem da cultura, entendida como ordem social. Neste sentido, a ordem social foi influenciada pela subordinação do feminino ao masculino, dominada pelo princípio da superioridade masculina.

É a partir do referido mito que a divisão sexual da citada sociedade deriva, no sentido desta pertencer à "ordem das coisas", dotada de naturalidade. Bourdieu destaca, neste sentido, que a ordem social legitima a dominação masculina. Assim, pode-se perceber que é o mundo social que constrói a concepção sexuada do corpo, aplicando divisões sexualizantes. Trata-se, portanto, de uma construção das diferenças existentes entre os "sexos biológicos", embasadas na dominação do masculino sobre o feminino.

Neste contexto, a visão social constrói a divisão anatômica entre homem e mulher, divisão esta considerada aparentemente natural. Tal naturalidade que fundamenta a visão social, que proporciona a referida naturalidade. Percebe-se a existência de uma retórica quanto ao tema, uma circularidade teórica. Sobre a referida retórica, Bourdieu destaca que a força da sociodiciea masculina é originada do condensamento, por esta, de duas operações, 
quais sejam: "[...] ela legitima uma relação de dominação inscrevendo-a em uma natureza biológica que é, por sua vez, ela própria, uma construção social naturalizada." (2014, p. 40, grifo do autor).

Trata-se de uma construção arbitrária da natureza biológica da referida dominação, que determina a organização simbólica da ordem natural e sexual, fundamentando um caráter natural da concepção androcêntrica da "divisão de trabalho sexual e da divisão sexual do trabalho e, a partir daí, de todo o cosmos." (2014, p. 40).

Portanto, pode-se perceber uma dominação pelo masculino, marcada pela divisão sexual, divisão esta legitimada pela sua natureza biológica, que conforme já ressaltado anteriormente, é uma construção social naturalizada. Com relação à referida dominação masculina, ao seu modo de imposição e à forma que esta é vivenciada, Bourdieu ressalta a existência de um nítido exemplo daquilo que ele chama de "violência simbólica".

A dominação masculina como um fenômeno marcado por uma violência simbólica. Neste sentido, partir-se-á à análise da referida violência, através da conceituação e reflexão acerca dos institutos do Poder Simbólico e da Violência Simbólica.

Bourdieu, em sua obra $O$ Poder Simbólico, destaca o referido poder como aquele que se espalha, que está presente em toda parte. Trata-se de um poder invisível, que só pode ser exercido com a aderência dos seus assujeitados, ou seja, com a cumplicidade daqueles que ignoram a sua sujeição a tal poder ou mesmo o fato de que perpetuam o referido. Trata-se de um poder de construção da realidade (BOURDIEU, 2007).

O referido poder simbólico exerce uma dominação que não funciona através da lógica pura das consciências cognoscentes, e sim através dos esquemas de percepção, avaliação e ação, constitutivos do habitus, os quais são transmitidos corporalmente, de corpo a corpo. São marcados por atividades inconscientes, aquém dos discursos. Portanto, majoritariamente, os habitus ficam isentos do controle consciente, das correções e transformações.

Como exemplo de tal isenção, Bourdieu destaca a defasagem entre as declarações e as práticas, citando os homens que se dizem a favor da igualdade entre os sexos, mas que não participam mais dos trabalhos domésticos do que aqueles que não são favoráveis a tal igualdade.

Bourdieu comenta que o poder simbólico é exercido sobre os corpos de forma direta e, como que por um passe de mágica, sem qualquer tipo de coação física. Entretanto, para tal magia funcionar ela precisa estar baseada em predisposições inseridas em profundidade nos 
corpos. O referido autor compara tais predisposições a "molas propulsoras", ao ilustrar a força exercida pelo poder simbólico como um "macaco mecânico", ou seja, com um gasto pequeno de energia.

Neste sentido, o poder simbólico estaria fundamentado em predisposições intrínsecas aos indivíduos, ou seja, disposições ensejadas por todo um trabalho de inculcação e incorporação realizado nos sujeitos que, em virtude dos referidos trabalhos, foram capturados pelo poder simbólico. Neste contexto, destaca Bourdieu (2007, p. 60-61):

Em outros termos, ela encontra suas condições de possibilidade e sua contrapartida econômica (no sentido mais amplo da palavra) no imenso trabalho prévio que é necessário para operar uma transformação duradoura dos corpos e produzir as disposições permanentes que ela desencadeia e desperta: ação transformada ainda mais poderosa por se exercer, nos aspectos mais essenciais, de maneira invisível e insidiosa, através da insensível familiarização com um mundo físico simbolicamente estruturado e da experiência precoce e prolongada de interações permeadas pelas estruturas de dominação.

Assim, o poder simbólico está fundamentado em um trabalho prévio, responsável por realizar uma transformação prolongada dos corpos e do cérebro, exercendo-se de maneira invisível e insidiosa.

Acerca do poder simbólico, pode-se concluir que este só pode se exercer através da colaboração daqueles aos quais ao referido poder estão subordinados, entretanto deve-se ressaltar que só se subordinam a este poder porque o constroem. Ou seja, só há subordinação ao poder simbólico porque os subordinados ao mesmo o constroem, a partir das predisposições (BOURDIEU, 2014).

Bourdieu, neste contexto, compara os agentes sociais, objetos do poder simbólico, à mônadas leibnizianas ${ }^{4}$, no sentido de destacar a harmonia entre os referidos agentes, que não precisam se comunicar ou mesmo colaborar para estarem de acordo.

Os agentes sociais corretamente socializados têm em comum estruturas lógicas, senão idênticas, pelo menos semelhantes, de sorte que eles são como mônadas leibnizianas, que não precisam necessariamente comunicar e colaborar para estarem de acordo. Os sujeitos sociais são, em certo sentido, mônadas leibnizianas. (2014b, p. 229)

Por sua vez, intimamente relacionada ao instituto da dominação simbólica, a violência simbólica consiste no meio de exercício do poder simbólico. Trata-se da utilização do poder

\footnotetext{
${ }^{4}$ Refere-se, neste contexto, à concepção de Leibniz sobre os atos de cada mônada, que para ele foram objetos de uma regulação antecipada, que proporcionou a adaptação destas aos atos de todas as outras. Trata-se de uma harmonia pré-estabelecida.
} 
simbólico por uma classe com fins de dominar outra. Neste sentido, destaca Bourdieu (2007, p. 11, grifo nosso):

É enquanto instrumentos estruturados e estruturantes de comunicação e de conhecimento que os sistemas simbólicos cumprem a sua função política de instrumentos de imposição ou de legitimação da dominação, que contribuem para assegurar a dominação de uma classe sobre outra (violência simbólica) dando o reforço da sua própria força às relações de força que as fundamentam e contribuindo assim, segundo a expressão de Weber, para a domesticação dos dominados.

No presente contexto, a referida concepção de classe é substituída pela noção do masculino, pela sobreposição do masculino sobre o feminino. Tem-se, portanto, uma dominação do masculino, uma dominação masculina, exercida através de uma violência simbólica.

Nos moldes do poder simbólico, a violência simbólica é exercida de forma invisível, sutil, insensível, às suas vítimas, através de vias simbólicas de conhecimento e comunicação, ou melhor, do desconhecimento, reconhecimento e sentimento.

Quanto ao conceito de violência simbólica, Bourdieu faz uma ressalva no sentido de que esta é entendida, supostamente, como oposta à violência física, real, efetiva; supondo-se que violência simbólica, consequentemente, seria uma violência "espiritual", desprovida de efeitos reais. O referido autor comenta que tal distinção é demasiadamente simplista e apresenta impropriedades, uma vez que a referida violência é objetivada nas coisas e incorporada nos corpos e nos habitus dos agentes, portanto o atributo "espiritual" não é suficiente para representá-la.

O filósofo Slavoj Žižek comenta a referida violência simbólica, em sua obra Violência: seis reflexões laterais. O referido autor sustenta que é a "violência subjetiva", a evidente e visível, que é a mais conhecida e que possui um maior destaque, representada por atos criminosos e de terror. Entretanto, para o referido autor, é necessário dar "um passo para trás", no sentido de nos desvencilharmos do referido "engodo", referindo-se à "violência subjetiva", que é exercida por um agente claramente identificável.

Para o filósofo, é necessária a percepção do cenário subjacente que conduz às referidas explosões, explosões no sentido de manifestações da violência visível, do terror. A "violência subjetiva" apenas seria uma explosão, uma expressão, propiciada por um cenário subjacente de violência. Uma violência invisível, suave. Trata-se do que ele chama de "violência objetiva", que é composta por duas subespécies, a violência simbólica e a violência sistêmica. 
A primeira, violência simbólica, para o autor, está ligada à linguagem e suas formas, que não está apenas nos casos evidentes e disseminados de dominação social que os discursos habitualmente reproduzem, inclui-se, também, uma forma mais fundamental de violência, pertencente à linguagem, ao império de um universo de sentido. A segunda, a violência sistêmica, está relacionada às consequências, geralmente negativas, do sistema econômico e político.

Žižek destaca que a "violência subjetiva" e a "objetiva" não podem ser verificadas do mesmo ponto de vista, uma vez que enquanto a "violência subjetiva" pode ser vista nitidamente, a "objetiva" aparece como se não houvesse violência, o que o referido autor chama de "grau zero de não violência". O Estado de coisas marcado pela normalidade e pacificidade é desequilibrado pela perturbação originada da "violência subjetiva", enquanto que a "objetiva" é intrínseca à referida normalidade e pacificidade do estado das coisas. A violência simbólica sustenta a referida normalidade, a normalidade do "nível zero de não violência", a partir da qual se pode perceber a manifestação da "violência subjetiva".

O autor emite uma crítica em relação à ênfase dada à "violência subjetiva", em face da "violência objetiva", no sentido de a referida ênfase estaria ligada a uma tentativa de deslocamento de atenções do lugar do problema, que seria a "violência objetiva". Nas palavras de Žižek (2014, n.p):

\begin{abstract}
Não haveria algo de suspeito, até mesmo sintomático, nesse foco sobre a violência subjetiva, a violência dos agentes sociais, indivíduos maléficos, aparelhos repressivos disciplinados, das multidões fanáticas? Não haveria aqui uma tentativa desesperada de desviar as atenções do verdadeiro lugar do problema, uma tentativa que, ao obliterar a percepção de outras formas de violência, se torne assim parte ativa delas?
\end{abstract}

Žižek ressalta que com o destaque dado à violência subjetiva, o objetivo é "mudar de assunto", tirar a atenção dos outros dois tipos de violência (simbólica e sistêmica), destacando apenas uma, a "violência subjetiva". A tarefa é resistir ao fascínio da referida violência, a fim de considerar a existência de uma estrutura complexa de interesses e fatores, atravessada pelos três tipos de violência.

A citada teoria desenvolvida por Žižek vai ser a base para uma posterior crítica feita pelo mesmo aos comunistas liberais, para os quais há problemas relevantes a serem resolvidos, como um dos que o referido autor cita: a fome na África. Entretanto, a crítica é que são eles os responsáveis pelos referidos males causados, almejando resolver tais problemas apenas para que suas vidas tenham um profundo sentido. Nas palavras do autor: 
"Do mesmo modo, os comunistas liberais de hoje em dia dão com uma das mãos o que o primeiro agarraram com a outra" (2014, n.p).

Neste contexto, Žižek destaca a necessária percepção dos variados tipos de violência, e não apenas da violência mais visível, mais fácil de enxergar pelos violentados. Deve-se atentar para a estrutura complexa de violência, que é formada pela referida violência visível, mas também, e principalmente, por violências sutis, "objetivas", que ensejam uma manifestação violenta, a violência "subjetiva". Neste sentido, destaca-se a importância analítica da violência sutil, simbólica, violência esta que, para Bourdieu, é o meio de exercício da dominação masculina.

Para Bourdieu, a dominação masculina está baseada no caráter objetivo das estruturas sociais e das atividades (re) produtivas, ambas embasadas na divisão sexual do trabalho produtivo e reprodutivo biológico e social; e nos esquemas próprios aos habitus. Quanto aos últimos, estes são moldados pelas referidas condições, funcionando como matrizes das percepções, dos pensamentos e das ações de todos os indivíduos do corpo social, partilhados universalmente e se impondo como transcendentes.

Assim como já se analisou no poder simbólico, a violência simbólica é marcada, também, pela aderência dos dominados aos dominantes, proporcionada pela falta de disposição para refletir sobre a dominação, tampouco sobre a relação dominante - dominado, uma vez que não possuem instrumentos de conhecimento que não estejam mergulhados na realidade criada pela dominação, o que os fazem achá-la natural, dotada de naturalidade.

Percebe-se, desta forma, que a referida dominação afeta o indivíduo em sua profundidade, ao ponto que este não consegue refletir, pensar, fora do campo de dominação a ele imposto. O trabalho de construção simbólica estará completo e realizado quando ocasionar uma "transformação profunda e duradoura dos corpos (e dos cérebros)" (Bourdieu, 2014, p. 40). Assim, percebe-se que a referida construção simbólica tem como objetivo impor uma forma de pensamento, de percepção do corpo, uma visão marcada pela superioridade masculina, visando naturalizar esse viés de pensamento através de uma máscara, a naturalização biológica.

A referida transformação profunda e duradoura realizada sobre os corpos e sobre os cérebros do corpo social tende a excluir do pensável e do factível tudo aquilo que possua características de pertencer a outro gênero, a fim de produzir dois modelos: homem viril e mulher feminina, que não são provenientes da natureza, mas da soma das relações sociais 
próprias da dominação. Trata-se de dois padrões produzidos a serem seguidos, sendo que aquele que não os seguirem será excluído, considerado anormal.

Traçando essa lógica com o sistema prisional, destaca-se que uma corrente de estudos feministas afirmou que as mulheres eram punidas mais severamente perante a justiça criminal, justamente pela discriminação de gênero que levava juízes a acreditar na discrepância entre a conduta de mulheres criminosas e a conduta esperada por mulheres era maior do que em relação aos homens, dessa forma eram punidas duplamente por terem cometido um crime e por transgredirem o comportamento esperado por elas (ISHIY, 2014).

Dessa forma, fica evidente que a transversalidade de gênero nas políticas públicas tem papel fundamental de orientar novas visões para a superação das desigualdades de gênero, inclusive, no sistema prisional.

Assim, Wiecko e Campos afirmam (2018, p. 6):

A transversalidade do gênero deve perpassar todo o sistema de justiça. Valemo-nos, aqui, do conceito de Maria Tereza Sadek (2010, p. 9), segundo o qual é mais amplo que o do Poder Judiciário. O sistema de justiça envolve diferentes agentes: os(as) juízes(as) de todos os graus de jurisdição; o(a) advogado(a) público(a) ou privado(a), o(a) defensor(a) público(a); os(as) funcionários(as) da justiça; peritos(as); os membros do Ministério Público; o(a) delegado(a) de polícia; e os agentes policiais, funcionários(as) da execução penal.

A partir destas concepções, pode-se sustentar que a dominação masculina se exerce através de uma violência simbólica, que limita as atividades de subversão por parte dos dominados. Bourdieu destaca que as estratégias simbólicas utilizadas pelas mulheres contra os homens permanecem dominadas, uma vez que estão pautadas na concepção androcêntrica. Trata-se de estratégias insuficientes para subverter a referida estrutura de dominação masculina, acabando por ratificar a situação de inferioridade imposta às mulheres.

Neste sentido, o preconceito contra o feminino é incorporado nos corpos e objetivado nas coisas, o que faz com que as mulheres ratifiquem tal preconceito, ou seja, que estas cometam atos de reconhecimento, de adesão à doxa. Trata-se de uma crença impensada, que constrói a violência simbólica sofrida por elas próprias.

E com base em estruturas de violência simbólica que as mulheres, ao longo da história, têm sido vítimas de uma armadilha social que as coloca numa posição de fragilidade, docilidade e submissão, elementos responsáveis por uma construção estereotipada de pessoas menos capazes. 


\section{PODER SIMBÓLICO, CÁRCERE E GÊNERO}

Quando se fala em matéria criminal, as mulheres também eram consideradas, fruto da tão aclamada docilidade, muito menos capazes de cometer crimes que os homens e quando os cometia, seria sempre sob a influência de um homem ou por motivos de paixão. Essa suposta incapacidade para o mundo do crime é um dos elementos que ajuda a fortalecer o universo feminino como inferior nos diversos campos sociais (FARIA, 2010).

É nessa ótica de dominação que se analisa, nesse segundo momento, a percepção do encarceramento feminino no Brasil, afinal, a lógica que persegue a existência feminina é de que são seres de segunda categoria, Simone de Beauvoir destaca que a mulher determina-se e diferencia-se em relação ao homem e não este em relação a ela; a fêmea é o inessencial perante o essencial. O homem é o sujeito, o absoluto; ela é o outro (1970, p. 10). Dessa forma, a visão androcêntrica atinge mulheres e crianças que estão por vezes condenadas ao cárcere, ainda que por tempo determinado, como no caso das crianças que nascem no sistema prisional e têm prazo para saírem ${ }^{5}$.

Dessa forma, analisa-se o encarceramento em massa sob a ótica de gênero e raça, o porquê das prisões serem tão presentes e ao mesmo tempo ausentes para a sociedade. Para tanto, utilizou-se, como marco teórico, as obras Estarão as prisões obsoletas? e Mulheres, raça e classe, da filósofa Angela Davis.

Nas palavras de Angela Davis (2018, p. 20):

A prisão se tornou um ingrediente essencial no senso comum. Ela está lá, à nossa volta. Não questionamos se deveria existir. Ela se tornou uma parte fundamental da nossa existência que é necessário um grande esforço de imaginação para visualizar a vida sem elas.

A sociedade (punitiva) não visualiza alternativa para o encarceramento; torna-se, assim, um mecanismo essencial para configurar uma sensação de segurança. Não se discute sobre o que ocorre lá dentro, já que, segundo o senso comum, “quem lá ingressou é porque merece e tem que permanecer", não importando as condições.

No que se refere a mulher encarcerada, esta mulher deveria desempenhar o papel de "dama", dando o exemplo moral e de castidade à sociedade, servindo à família e ao esposo, destarte, a Igreja se sentindo ameaçada decidiu adotar medidas rígidas, dando início à "caça às bruxas" (PIZOLOTTO, 2014).

\footnotetext{
${ }^{5}$ Lei 11.942/2009. Art. 83, § $2^{\circ}$ Os estabelecimentos penais destinados a mulheres serão dotados de berçário, onde as condenadas possam cuidar de seus filhos, inclusive amamentá-los, no mínimo, até 6 (seis) meses de idade.
} 
Esse processo pode ser notado na dificuldade que as mulheres enfrentam nos presídios dos estados brasileiros, pois é comum, na literatura especializada sobre o tema, ler relatos de presídios femininos que não tinham o aparato mínimo para as necessidades básicas da mulher, por exemplo, a falta de absorventes para fornecer nos períodos menstruais (QUEIROZ, 2015).

Sendo assim, debater sobre o sistema carcerário sob a ótica de dominação masculina, gênero e raça e os seus reflexos na vida dessas mulheres é fundamental para compreender a gravidade da invisibilidade de vidas encarceradas, assim como a desigualdade entre homens e mulheres no sistema prisional.

O mundo do crime não é uma realidade apartada da ordem social desigual entre homens e mulheres - ao contrário, certas hierarquias, regras e práticas são exacerbadas no mundão. Uma delas é a da dominação masculina; a segunda é a da responsabilidade feminina pelo cuidado de filhos (DINIZ, 2017).

Nesse sentido, destaca Luciana Ramos (2012, p. 62):

As escassas informações sobre a delinquência feminina se dão, não só pela situação, culturalmente construída, de subalternidade das mulheres, de ocultação dos papéis por elas desenvolvidos na sociedade, muito embora, a ocupação do espaço público tenha ganhado cada vez mais um colorido feminino, mas também ocorre pelo baixo índice geral do encarceramento feminino (tomado com relação aos índices masculinos).

A constatação de que as mulheres encarceradas são, em sua maioria, primárias, jovens, pertencentes a grupos étnicos minoritários, pobres, mães solteiras, com baixa escolaridade e sem qualificação profissional, e que no momento da sua prisão portavam pequena quantidade de drogas, não possuíam relação com organizações criminosas, não praticaram atos de violência, tampouco portavam armas, demonstra a urgência de elaborarem-se políticas sociais mais eficazes, razoáveis e proporcionais, que considerem as especificidades da conduta feminina e as funções efetivamente exercidas pelo cárcere (ISHIY, 2014).

Assim, citando Makki e Santos (2010), apesar de estarem expostas aos mesmos fatores sociais que atingem a nossa população, as mulheres sofrem, além desses, fatores culturais característicos do gênero, como maus tratos e abuso sexuais sofridos durante a infância e adolescência, violência doméstica por parte de seus companheiros, gravidez precoce, entre outros.

De acordo com Bárbara Musumeci Soares (2002) mais de 95\% das mulheres encarceradas foram vítimas de violência em algumas dessas situações: na infância, por parte 
de seus responsáveis; na vida adulta, por parte dos maridos e quando presas por parte de policiais civis, militares ou federais.

Com base nos dados do Infopen 2018, é possível o perfil da mulher encarcerada no Brasil. Nota-se que $50 \%$ da população prisional feminina é formada por jovens, ou seja, de 18 a 29 anos (BRASIL, 2018, p. 38), conforme classificação do Estatuto da Juventude, Lei n ${ }^{\circ}$ 12.852/2013 (BRASIL, 2018).

Outro aspecto abordado e disponibilizado pelo Infopen 2018 é referente à raça e à cor da população carcerária feminina; segundo os dados, $62 \%$ da população é composta por mulheres negras (BRASIL, 2018, p. 40). É possível afirmar que, entre a população maior de 18 anos, existem aproximadamente 40 mulheres brancas privadas de liberdade para cada grupo de 100 mil mulheres brancas, e existem 62 mulheres negras na mesma situação para cada grupo de 100 mil mulheres negras, o que expressa a disparidade entre os padrões de encarceramento de mulheres negras e brancas no Brasil (BRASIL, 2018).

Nessa perspectiva, podemos inferir que o sistema penal não foi concebido para atingir a todos os delitos e delinquentes, sob o risco de decretar sua própria falência. Trata-se de uma estrutura vocacionada para atingir os crimes relacionados aos setores socialmente mais vulneráveis (FLAUZINA, 2006).

Nesse sentido, temos um sistema prisional com pessoas selecionadas, tornando uma seleção bem homogênea, afinal, prender é a solução mais indicada para determinada parcela da sociedade.

Ana Flauzina (2006) destaca que as atribuições do sistema penal relacionam-se mais concretamente ao controle e perseguição de determinados indivíduos do que com a contenção das práticas delituosas.

Nesse sentido, Angela Davis (2018, p. 69) destaca que:

[...] Seguindo o modelo dominante de prisões femininas durante o período, os regimes de Alderson se baseavam no pressuposto de que mulheres "criminosas" podiam ser regenerar por meio da assimilação de comportamentos femininos adequados - isto é, tornando-se especialistas na vida doméstica -, especialmente cozinhar, limpar e costurar. Obviamente, um treinamento destinado a produzir esposas e mães melhores dentre as mulheres brancas de classe média produzia empregadas domésticas qualificadas dentre as mulheres negras e pobres.

Sempre houve tendência a encarar as mulheres que foram punidas publicamente pelo Estado por seu "mau comportamento" como significativamente mais "anormais" e muito mais 
ameaçadoras para a sociedade do que suas numerosas contrapartes masculinas (DAVIS, 2018).

Nessa lógica de dominação e subversão, as criminalizadas o eram, em geral, pelo seu comportamento não adequado à figura do feminino e o poder do Estado, através de uma atitude patriarcal, buscava mecanismos para a "educar" as "desajustadas sociais". O controle punitivo ganhou força na primeira metade do século $\mathrm{XX}$ com novas teorias sobre a criminalidade da mulher, quase todas ligadas à "moralidade", e com a criação de tipos penais específicos para controlar as que não seguiam ao padrão desejado. Como as mulheres eram consideradas menos evoluídas e mais frágeis, o cometimento do crime era ligado à educação e não a violência, portanto o tratamento de "criminosas" deveria ser distinto do caso dos homens. Elas precisavam receber do Estado a formação que não haviam recebido do pai (FARIA, 2013).

Ao se pensar no "Ser Mulher", comumente, tem-se a imagem construída a partir da visão de que mulheres têm uma natureza única e que são possuidoras de uma "bondade ontológica". Esta concepção acerca das mulheres tem como corolário a visão destas como "vítimas do destino". Desta forma, historicamente, a figura da mulher foi colocada em um patamar de submissão, repressão e/ou vitimização, quando se fala em situações de violência (SILVA, 2008).

Davis (2018) assevera que quando consideramos o impacto da classe e da raça, podemos dizer que, para as mulheres brancas e ricas, essa equalização tende a servir como evidência de transtornos emocionais e mentais, mas para as mulheres negras e pobres, isso indica criminalidade.

Violências psicológicas, físicas e morais são comumente relatadas pelas presas; o abuso sexual cometido pelos guardas nas prisões é traduzido em hipersexualidade das prisioneiras (DAVIS, 2018). A ideia de que os "desvios" femininos sempre tem uma dimensão sexual persiste em nossa época, e essa intersecção de criminalidade e sexualidade continua a ser racializada (DAVIS, 2018).

Angela Davis destaca que:

A escravidão se sustentava tanto na rotina do abuso sexual quanto no tronco e no açoite. Impulsos sexuais excessivos, existentes ou não entre os homens brancos como indivíduos, não tinham nenhuma relação com essa verdadeira institucionalização do estupro. A coerção sexual, em vez disso, era uma dimensão essencial das relações sociais entre o senhor e a escrava. Em outras palavras, o direito alegado pelos proprietários e seus agentes sobre o corpo das escravas era uma 
expressão direta de seu suposto direito de propriedade sobre pessoas negras como um todo (DAVIS, 2016, p. 180).

As violações pelas quais mulheres e, especialmente, as mulheres negras sofrem, têm raízes na escravidão, na construção de sociedades racistas e machistas, de que a mulher é um objeto, ou de que a mulher não possui identidade sem a presença masculina. Rita Segato destaca:

\begin{abstract}
Por minha parte, afirmo que os gêneros constituem a emanação, por meio da sua encarnação em atores sociais ou personagens míticos, de posições numa estrutura abstrata de relações que implica uma ordenação hierárquica do mundo e contém a semente das relações de poder na sociedade. Eles seriam, deste ponto de vista, transposições da ordem cognitiva à ordem empírica. Poderia se dizer que a estrutura, a partir da primeira cena em que participamos (a cena familiar - ou substituta primigênia, não importa a cultura de que se trate ou o grau de desvio em relação ao padrão social numa cultura particular) se transveste de gênero, emerge nas caracterizações secundárias com os traços do homem e a mulher, e nos seus papéis característicos (SEGATO, 1998, p.3).
\end{abstract}

Nessa perspectiva, Mírian Zafalon destaca que:

Graças a Butler e a outras feministas a mobilização contra a dominação masculina ocupa espaço em vários lugares onde há, na contemporaneidade, repressão à mulher e desigualdade entre os sexos. Entretanto, o papel de mulher-vítima não é pertinente e nem propício para rechaçar as discriminações e violências contra as mulheres, uma vez que vitimizá-las, fazendo-as parecer mais frágeis do que realmente são, reitera a hegemonia masculina. Quando as mulheres aceitam o posto de vítimas da situação, injustiçadas pelos desmandos masculinos, são capazes de abrir mão de sua autonomia e emancipação, movidas pela ideia de uma "natureza feminina". Contra a dominação e a vitimização surge a ideia pós-moderna de desconstrução das perspectivas de identidade, destacando-se a subjetividade feminina em detrimento dos conceitos essencialistas de sujeito (ZAFALON, 2014, p. 4).

A ótica de identidade é um fator construído paulatinamente, no interior do discurso e que obedece a hierarquia de poder. Sendo assim, o discurso androcêntrico produz um sentido específico para os gêneros, solidificando a divisão sexual do trabalho, estabelecendo diferenças que são "naturalizadas" arbitrariamente. A identidade feminina é constituída, portanto, a partir do ato de liderança e dominação do homem, conferindo à mulher, como resultado, a exclusão (ZAFALON, 2014).

Dessa forma, os controles sociais, por diversas vezes, vão se pautando nessas bases estruturais. Diante disso, dados sobre a saúde da mulher, trazidos por Flauzina (2006), citando pesquisa de Sueli Carneiro, discorre:

O útero da mulher negra não tem valor, então qualquer mioma tem a indicação de retirada do útero. Souza aponta que as condutas médicas são diferentes diante de uma mulher se ela é negra ou se ela é branca. A conduta conservadora de uso de remédios ou expectantes é geralmente indicada para a mulher branca de qualquer classe social; ao contrário, para as mulheres negras, é indicada a histerectomia. 
A visão de que a mulher é mero objeto, passível de sofrer qualquer tipo de violação, apenas pela sua condição de ser mulher, sendo agravadas essas violações quando são mulheres negras é estruturante de um sistema pautado na invisibilidade de sujeitos sociais subalternizados.

Os direitos violados, seja a saúde, a educação ou o trabalho, influencia na forma como as mulheres viverão suas vidas, quanto maior for a interseccionalidade - o alcance das dimensões de gênero, raça e classe - maior será a vulnerabilidade da pessoa, segundo dados do Infopen, 62\% da população é composta por mulheres negras (BRASIL, 2018, p. 40).

Davis (2018) afirma que estudos sobre prisões femininas em todo o mundo indicam que este abuso é uma forma de punição permanente, embora não reconhecida, à qual as mulheres que têm o infortúnio de serem mandadas para a prisão são submetidas.

Dessa maneira, a combinação destrutiva de racismo e misoginia, reforça a atuação seletiva e punitivista do sistema de justiça criminal, mantendo todas as suas terríveis consequências nas prisões femininas (DAVIS, 2018).

Ainda nesse viés, destaca-se que a perspectiva de gênero tem que ser analisada no sistema de justiça, Ela Wiecko e Carmen de Campos afirmam que:

\begin{abstract}
Para incorporar a perspectiva de gênero no sistema de justiça, não basta ter boa vontade, utilizar a expressão gênero ou meramente dizer que se está aplicando o gênero. É necessário levar em conta o contexto social e jurídico de cada país e diagnosticar as barreiras visíveis e invisíveis que obstaculizam o acesso igual das mulheres à justiça. Uma metodologia feminista, no campo do direito, implica analisar a aplicação da perspectiva baseada no gênero, na composição dos órgãos do sistema de justiça, na tomada de decisões das políticas institucionais, na elaboração legislativa, na investigação, processo e julgamento de casos em que as mulheres são autoras ou vítimas e, ainda, na interpretação (doutrina) $(2018$, p.8).
\end{abstract}

Muito se fala sobre a perspectiva de gênero, mas, afinal, o que é gênero? Para responder a essa pergunta, utilizamos das concepções de Ela Wiecko e Carmen Hein de Campos (2018, p. 3), as quais destacam a que associação sexo-gênero foi explicitada na Recomendação Geral 33 da Convenção sobre a eliminação de todas as formas de discriminação contra a mulher:

A associação sexo-gênero foi explicitada na Recomendação Geral 33, a qual no seu item 7 explica que "a discriminação pode ser dirigida contra as mulheres por motivo de sexo e gênero. Gênero refere-se a identidades, atributos e papéis socialmente construídos para mulheres e homens e ao significado cultural imposto pela sociedade às diferenças biológicas, que se reproduzem constantemente no sistema de justiça e suas instituições" (CEDAW, 2015). 
Analisando sob a perspectiva decolonial, Camila de Magalhães sustenta que:

Assim, sustento que raça, sexo e gênero são categorias que devem ser examinadas em conjunto porque produzidas em conjunto e não apenas porque produzem estereótipos ou discriminações diferentes quando observadas em conjunto na experiência dos sujeitos. Desse modo, ainda que permaneça a dúvida sobre se "todas fazemos gênero?", uma resposta preliminar é que, como atribuição de sentido aos corpos e suas funções reprodutivas, talvez sim, todas façamos. Mas que, como distribuição de poder binária hierarquizante, a resposta não é única ou rápida e é isso que também nos exige usar o gênero como categoria de análise decolonial: como forma de investigar o que a colonialidade do gênero apagou, destruiu ou invisibilizou e como as noções de gênero da modernidade colonial que hoje discutimos ou combatemos são construções que usam da raça e do sexo de modo articulado para preencher a oposição entre humanos e não-humanos (MAGALHÃES, 2018, p. 77).

Sendo assim, diante desse conceito de gênero, não é difícil entender o papel atribuído às mulheres, pensadas e repensadas em segundo plano, o gênero estrutura o sistema prisional.

Davis destaca (2018, p. 70):

Apesar da disponibilidade de retratos detalhados da vida em prisões femininas, tem sido extremamente difícil persuadir o público - e até mesmo, por vezes, os ativistas antiprisionais que se preocupam sobretudo com as dificuldade dos prisioneiros do sexo masculino - sobre a centralidade do gênero na compreensão do sistema de punição estatal.

Ela Wiecko e Carmen de Campos, ao discorrerem sobre a implementação da perspectiva de gênero na legislação e nas políticas, ressaltam (2018, p. 5):

Com efeito, não é fácil a tarefa de incorporar uma perspectiva de gênero na elaboração, na execução e na avaliação de políticas públicas. Não se trata apenas de contemplar as demandas das mulheres, mas de ter presente o aspecto relacional e estrutural da desigualdade entre mulheres e homens para construir as soluções a fim de alcançar a equidade.

A dificuldade de analisar a perspectiva de gênero tem viés estrutural e cultural da sociedade; a desigualdade ainda é visível, quando alguém se propõe a pesquisar o sistema prisional, especificamente, o feminino, deve ter em vista a perspectiva de gênero, assim como a perspectiva de raça.

No cenário brasileiro diante de dados e estudos realizados sobre as prisões, é notória a disparidade entre brancos e negros no cárcere, bem como as demandas de homens e mulheres são distintas. Como continuamos negando questões tão fundamentais para alcançarmos, quem sabe um dia, a equidade entre essas diferenças?.

\section{CONSIDERAÇÕES FINAIS}


A partir da exposição dos principais elementos da teoria da dominação masculina de Pierre Bourdieu, pôde-se compreender os efeitos do poder e da violência simbólica masculina, incidentes sobre o corpo e o cérebro dos indivíduos, possuidores de um forte poder de persuasão, de formação de atos e ideias, que ultrapassa a ordem social, alcançando um patamar de uma “ordem cósmica', ou seja, torna-se intrínseco à figura do homem e da mulher. Uma lógica priorizadora do homem em desfavor da mulher.

Concepções e percepções que fazem com que os indivíduos reproduzam a referida lógica de dominação de forma involuntária, uma vez que o referido poder simbólico é incorporado nos corpos e nas mentes dos indivíduos e objetivado nos objetos, criando-se uma realidade, uma realidade construída, que aliena os indivíduos quanto à relação entre dominantes e dominados e até mesmo em relação à lógica da dominação simbólica.

A partir do entendimento da referida alienação, passou-se a analisar a mulher no cárcere, investigando-se em que medida o cárcere é um instrumento correlacionado a uma perspectiva masculina subjugadora da mulher.

Sustentou-se que a mulher é encarada como um mero objeto, um sujeito matável em detrimento de seu gênero, que estaria exposta a qualquer tipo de violação. Trata-se de um sistema ratificador da invisibilidade de sujeito marginalizados, uma instituição masculina, excludente do feminino, violentador do mesmo.

Simbolicamente, o cárcere é projetado em níveis do masculino dominar o feminino. Eis a ponte de ligação entre a construção teórica pautada na teoria de Pierre Bourdieu e a mulher no cárcere. Eis que o mesmo é atravessado por uma lógica de poder invisível, doce, sedutora, que coordena os dominados de uma forma sútil o bastante para passar quase desapercebida.

\section{REFERÊNCIAS BIBLIOGRÁFICAS}

BRASIL, Levantamento Nacional de Informações Penitenciárias - INFOPEN Mulheres $2^{\mathrm{a}}$ edição. Brasília, DF, 2018. 79 p. Disponível em http://depen.gov. br/DEPEN/depen/sisdepen/infopen-mulheres/infopenmulheres_arte_07-03-18. pdf Acesso em 22 mai. 2019.

BOURDIEU, Pierre. O poder simbólico. $4^{\mathrm{a}}$ ed. Rio de Janeiro: Bertrand Brasil, 2001.

BOURDIEU, Pierre. A dominação masculina - A condição feminina e a violência simbólica. $1^{\mathrm{a}}$ ed. Rio de Janeiro: Bestbolso, 2014a. 
BOURDIEU, Pierre. Sobre o Estado. $1^{\text {a }}$ ed. São Paulo: Companhia das Letras, 2014b.

BUTLER, Judith. Problemas de gênero - Feminismo e subversão da identidade. $7^{\mathrm{a}}$ ed. Rio de janeiro: Civilização brasileira, 2014.

CASTILHO, E.W.V, CAMPOS, C.H. Sistema de justiça criminal e perspectiva de gênero. Disponível em https://bibliotecadigital.fgv.br/dspace/bitstream/handle/10438/24904/IBCCRIMOs\%20obsta\%CC\%81culos\%20impostos\%20a\%CC\%80s\%20mulheres\%20nas\%20visitas\%2 0aos\%20presos\%20como\%20forma\%20de\%20injustic\%CC\%A7a\%20de\%20ge\%CC\%82ner o\%20no\%20Tribunal\%20do\%20Distrito\%20Federal.pdf?sequence=1\&isAllowed $=\mathrm{y}$. . Acesso em: 9 de março de 2019.

DAVIS, Angela. Estarão as prisões obsoletas?. 1 ed. Rio de Janeiro: Difel, 2018.

DAVIS, Angela. Mulheres, raça e classe. 1 ed. São Paulo: Boitempo, 2016.

DE BEAUVOIR, Simone. O Segundo Sexo. V. 1 e 2. Tradução de Sérgio Milliet. Rio de Janeiro: Nova Fronteira, 1980.

DINIZ, Debora. Meninas fora da lei: a medida socioeducativa de internação no Distrito Federal.- Brasília : LetrasLivres, 2017.

FARIA, Thaís. A mulher e a criminologia: Relações e paralelos entre a história da criminologia e a história da mulher no Brasil. Disponível em: http://www.publicadireito.com.br/conpedi/manaus/arquivos/anais/fortaleza/3310.pdf. Acesso em: 6 de agosto de 2018.

FARIA, Thaís. Memória de um silêncio eloquente: A criminalização das mulheres no Brasil na primeira metade do século XX. Tese apresentada ao Programa de Pós-Graduação da Faculdade de Direito da Universidade de Brasília. 2013. Disponível em: http://repositorio.unb.br/bitstream/10482/16696/1/2013 ThaisDumetFaria.pdf. Acesso em 3 de fevereiro de 2019.

FLAUZINA, Ana. Corpo negro caído no chão: o sistema penal e o projeto genocida do estado brasileiro. Dissertação apresentada ao Programa de Pós-Graduação em Direito da Universidade de Brasília. 2006. Disponível em: http://repositorio.unb.br/handle/10482/5117?mode=full. Acesso em: 10 de setembro de 2018.

GOMES, Camilla de Magalhães. Gênero como categoria de análise decolonial. Disponível em: $\quad$ http://www.scielo.br/scielo.php?pid=S1519$\underline{60892018000100065 \& \text { script}=s c i \_a b s t r a c t \& t \operatorname{lng}=p t}$. Acesso em 15 de junho de 2019.

ISHIY, Karla. A desconstrução da Criminalidade Feminina. Dissertação apresentada ao Programa de Pós-Graduação em Direito da Universidade de São Paulo. 2014. Disponível em: 
http://www.teses.usp.br/teses/disponiveis/2/2136/tde-11022015-082103/en.php. Acesso em: 10 de julho de 2018.

MAKKI, Salma Hussein; SANTOS, Marcelo Loeblein dos. Gênero e criminalidade: Um olhar sobre a mulher encarcerada no Brasil. In: Âmbito Jurídico, Rio Grande, XIII, n. 78, jul 2010. Disponível em: http://ambitojuridico.com.br/site/index.php?n_link=revista_artigos_leitura\&artigo_id=8080. Acesso em: 25 de agosto de 2018.

PIZOLOTTO, Leticia. A lei 11.343/2006 e o aumento de mulheres encarceradas. Trabalho de Conclusão de Curso de Graduação em Direito na Universidade Regional do Noroeste do Estado do Rio Grande do Sul. 2014. Disponível em: http://bibliodigital.unijui.edu.br:8080/xmlui/handle/123456789/2553. Acesso em: 9 de agosto de 2018.

RAMOS, Luciana de Souza. Por amor ou pela dor? Um olhar feminista sobre o encarceramento de mulheres por tráfico de drogas. Dissertação apresentada ao Programa de Pós-Graduação da Universidade de Brasília. 2012. Disponível em: http://repositorio.unb.br/bitstream/10482/13758/1/2012_LucianadeSouzaRamos.pdf. Acesso em: 12 de dezembro de 2018.

SEGATO, Rita Laura. Os percursos do gênero na antropologia e para além dela. Disponível em http://www.miniweb.com.br/Historia/artigos/i_antiga/pdf/serie236empdf.pdf. Acesso em 15 de junho de 2019.

ZAFALON, Mírian. A identidade feminina à sombra da dominação masculina: uma leitura de camarão no jantar, de Sonia Coutinho. REVISTA LETRAS. Curitiba - v.16, n. 19, jul./dez. 2014 - UTFPR. Disponível em: //periodicos.utfpr.edu.br/rl. Acesso em 5 de junho de 2019.

ŽIŽEK, Slavoj. Violência: seis reflexões laterais. São Paulo: Boitempo, 2014. 